\title{
Predicting outcomes to optimize disease management in inflammatory bowel disease in Japan: their differences and similarities to Western countries
}

\begin{abstract}
Taku Kobayashi ${ }^{1}$, Tadakazu Hisamatsu ${ }^{2}$, Yasuo Suzuki ${ }^{3}$, Haruhiko Ogata ${ }^{4}$, Akira Andoh ${ }^{5}$, Toshimitsu Araki ${ }^{6}$, Ryota Hokari ${ }^{7}$, Hideki Iijima ${ }^{8}$, Hiroki Ikeuchi ${ }^{9}$, Yoh Ishiguro ${ }^{10}$, Shingo Kato ${ }^{11}$, Reiko Kunisaki $^{12}$, Takayuki Matsumoto ${ }^{13}$, Satoshi Motoya ${ }^{14}$, Masakazu Nagahori ${ }^{15}$, Shiro Nakamura ${ }^{16}$, Hiroshi Nakase $^{17}$, Tomoyuki Tsujikawa ${ }^{18}$, Makoto Sasaki $^{19}$, Kaoru Yokoyama ${ }^{20}$, Naoki Yoshimura ${ }^{21}$, Kenji Watanabe $^{22}$, Miiko Katafuchi ${ }^{23}$, Mamoru Watanabe ${ }^{15}$, Toshifumi Hibi ${ }^{1}$

${ }^{1}$ Center for Advanced IBD Research and Treatment, Kitasato University Kitasato Institute Hospital, Tokyo, ${ }^{2}$ The Third Department of Internal Medicine, Kyorin University School of Medicine, Mitaka, ${ }^{3}$ Department of Internal Medicine, Toho University Sakura Medical Center, Sakura, ${ }^{4}$ Center for Diagnostic and Therapeutic Endoscopy, Keio University School of Medicine, Tokyo, ${ }^{5}$ Department of Gastroenterology, Shiga University of Medical Science, Otsu, ${ }^{6}$ Department of Gastrointestinal and Pediatric Surgery, Mie University Graduate School of Medicine, Tsu, ${ }^{7}$ Division of Gastroenterology and Hepatology, Department of Internal Medicine, National Defense Medical College, Tokorozawa, ${ }^{8}$ Department of Gastroenterology and Hepatology, Graduate School of Medicine, Osaka University, Suita, ${ }^{9}$ Department of Inflammatory Bowel Disease, Division of Surgery, Hyogo College of Medicine, Nishinomiya, ${ }^{10}$ Department of Gastroenterology and Hematology, Hirosaki National Hospital, Hirosaki, ${ }^{11}$ Department of Gastroenterology and Hepatology, Saitama Medical Center, Saitama Medical University, Kawagoe, ${ }^{12}$ Inflammatory Bowel Disease Center, Yokohama City University Medical Center, Yokohama, ${ }^{13}$ Division of Gastroenterology, Department of Internal Medicine, School of Medicine, Iwate Medical University, Morioka, ${ }^{14}$ IBD Center, Sapporo-Kosei General Hospital, Sapporo, ${ }^{15}$ Department of Gastroenterology and Hepatology, Tokyo Medical and Dental University, Tokyo, ${ }^{16}$ Department of Inflammatory Bowel Disease, Hyogo College of Medicine, Nishinomiya, ${ }^{17}$ Department of Gastroenterology and Hepatology, Sapporo Medical University School of Medicine, Sapporo, ${ }^{18}$ Department of Gastroenterology and Hepatology, Higashi-Ohmi General Medical Center, Higashiomi, ${ }^{19}$ Division of Gastroenterology, Department of Internal Medicine, Aichi Medical University School of Medicine, Nagakute, ${ }^{20}$ Department of Gastroenterology, Kitasato University School of Medicine, Sagamihara, ${ }^{2 l}$ Division of Gastroenterology, Department of Medicine, Tokyo Yamate Medical Center, Tokyo, ${ }^{22}$ Department of Intestinal Inflammation Research, Hyogo College of Medicine, Nishinomiya, ${ }^{23}$ Medical Affairs, Medical, AbbVie GK, Tokyo
\end{abstract}

Inflammatory bowel disease (IBD), including Crohn's disease (CD) and ulcerative colitis (UC), is a chronic inflammatory disease of the gastrointestinal tract, with increasing prevalence worldwide. IBD Ahead is an international educational program that aims to explore questions commonly raised by clinicians about various areas of IBD care and to consolidate available published evidence and expert opinion into a consensus for the optimization of IBD management. Given differences in the epidemiology, clinical and genetic characteristics, management, and prognosis of IBD between patients in Japan and the rest of the world, this statement was formulated as the result of literature reviews and discussions among Japanese experts as part of the IBD Ahead program to consolidate statements of factors for disease prognosis in IBD. Evidence levels were assigned to summary statements in the following categories: disease progression in CD and UC; surgery, hospitalization, intestinal failure, and permanent stoma in CD; acute severe UC; colectomy in UC; and colorectal carcinoma and dysplasia in IBD. The goal is that this statement can aid in the optimization of the treatment strategy for Japanese patients with IBD and help identify high-risk patients that require early intervention, to provide a better long-term prognosis in these patients. (Intest Res 2018;16:168-177)

Key Words: Crohn disease; Colitis, ulcerative; Prognosis; Colorectal neoplasms; Consensus

Received July 15, 2017. Revised September 22, 2017.

Accepted October 19, 2017. Published online December 7, 2017 Correspondence to Tadakazu Hisamatsu, The Third Department of Internal Medicine, Kyorin University School of Medicine, 6-20-2 Shinkawa, Mitaka 181-8611, Japan. Tel: +81-422-47-5511, Fax: +81-422-71-5381, E-mail: thisamatsu@ks.kyorin-u.ac.jp

\section{INTRODUCTION}

Optimization of the treatment strategy for patients with IBD or identifying high-risk patients who require early or intensive therapy is necessary to prevent progression that may

๑ Copyright 2018. Korean Association for the Study of Intestinal Diseases. All rights reserved.

This is an Open Access article distributed under the terms of the Creative Commons Attribution Non-Commercial License (http://creativecommons.org/licenses/by-nc/4.0)

which permits unrestricted non-commercial use, distribution, and reproduction in any medium, provided the original work is properly cited. 
lead to a poor long-term outcome and to avoid unnecessary or potentially harmful treatments in patients with less severe disease. This includes being able to predict specific disease complications, including extension of disease in UC, change of disease behavior and/or location in $\mathrm{CD}$, the need for surgery, and the development of colorectal cancer (CRC).

IBD Ahead is an international educational program that aims to explore questions commonly raised by clinicians regarding various aspects of IBD care and to consolidate available published evidence and expert opinion into a consensus for the optimization of IBD management. Gastroenterologists from 32 countries participated at both national and international meetings. The program's goal was to provide practical answers to questions raised in daily clinical practice based on available evidence and the participants' clinical experience. Recommendations by the participants were discussed and integrated based on national meetings held in the participating countries. Recently, an international statement was published by the IBD Ahead program on adverse prognostic factors in IBD. ${ }^{1}$

Discussions among Japanese experts in the management of IBD suggested that there were differences in prognostic factors in Japanese patients with IBD from those reported by the international statement. The epidemiology, clinical characteristics, risk factors, management, and prognosis of IBD differ between Western countries and East Asian countries, as well as within East Asia, including Japan. ${ }^{2-4}$ Genetic characteristics also differ between Japanese and Western patients with IBD, ${ }^{5,6}$ underscoring the importance of country and population-specific guidelines for the management of IBD. Consequently, this article consolidates statements of factors for disease prognosis in IBD approved by Japanese IBD experts as part of the IBD Ahead program, and suggests their effective use in IBD management.

\section{METHODS}

As previously described for the international consensus statement, ${ }^{1}$ the Global Steering Committee (GSC) of the IBD Ahead 2014 educational program identified key topics of interest or uncertainty in understanding prognostic factors in IBD; clinical questions relating to these topics were then developed. A literature search was conducted by the IBD Ahead GSC, and draft statements were developed. National meetings were then held in 32 countries to produce the international consensus statement. Participants reviewed, voted, and provided expert opinion and local perspectives on the statements; this feedback was used by the GSC to produce a consolidated set of statements, which has been published. ${ }^{1}$ The national advisory board meeting consisting of 23 Japanese experts in the management of IBD was held in Japan in August 2014. Expert opinion from this meeting was integrated with the international results of the global plan to create the consensus statements. The Japanese IBD experts reviewed this response draft and combined their results with the literature search results of the IBD Ahead GSC and Japanese expert opinion, with a focus on clinical applications relating to predictive factors in IBD management in the Japanese setting. An updated literature search of IBD prognostic factors, including those specific to Japanese patients, was also performed. These findings were subsequently incorporated into this document to report Japanesespecific results related to the consensus statements and to report information that was not captured by the initial literature review of the IBD Ahead GSC.

Evidence levels (ELs) were assigned based on this updated literature search using University of Oxford Centre for evidence-based medicine 2011 criteria (http://www.cebm.net/ wp-content/uploads/2014/06/CEBM-Levels-of-Evidence2.1.pdf). The Japanese experts also scored each statement by voting according to their level of agreement, with 1 indicating strong disagreement and 9 indicating strong agreement. If $\geq 75 \%$ of participants scored the statement within the 7 to 9 range, the statement was deemed to be agreed upon. If $<75 \%$ of participants scored within this range, the statement was debated and revised, and a second vote was taken. Again, if $\geq 75 \%$ of participants scored the statement within the 7 to 9 range, the statement was deemed to be agreed upon. The degree of agreement (\%) reflects the ratio of doctors who assigned a score of 7 to 9 . The average score is the average of the Japanese experts' scores.

\section{CONSENSUS STATEMENTS}

\section{Disease Progression in CD}

\begin{tabular}{|lc|}
\hline Summary statement & $\begin{array}{c}\text { Average agreement } \\
\text { score and rate of } \\
\text { agreement }\end{array}$ \\
\hline 1. At the time of diagnosis, extensive \\
small-intestinal lesions (EL2) and sig- \\
nificant upper gastrointestinal tract \\
disease (EL3) are predictive factors for \\
complicated disease behavior in CD.
\end{tabular}


2. Young age at diagnosis, need for steroids at first flare, and perianal disease at diagnosis predict a disabling course of CD (EL3).

3. Smoking can predict the need for therapy intensification in CD (EL3), development of complicated disease behavior (EL3), and the need for surgery (EL3).

4. Endoscopic severity of CD predicts the formation of fistulae (EL4) and the need for surgery (EL3).

As indicated in the international consensus statement, ${ }^{1}$ disease location, such as ileal and ileocolonic versus colonic, and upper gastrointestinal tract or rectal involvement are predictors of disease progression in CD. Independent factors present at diagnosis and significantly associated with a disabling course at 5 years include age $<40$ years (OR, 2.1; 95\% CI, 1.3-3.6), presence of perianal disease (OR, 1.8; 95\% CI, 1.2-2.8), and an initial requirement for steroids (OR, 3.1; 95\% CI, 2.2-4.4). ${ }^{7}$

A variety of studies, as reported in the international consensus statement, ${ }^{1}$ have shown that smoking is associated with stenosing/fistulizing behavior, need for steroids or immunomodulators, need for surgery, and disease recurrence following surgery. However, in Asian populations, some studies have shown different associations of smoking with CD compared to that found in Caucasian populations. For example, the same detrimental effect has not been seen in a Chinese population. ${ }^{8}$ In the prospective Asia-Pacific Crohn's and Colitis Epidemiology Study (ACCESS) study, which included patients from multiple countries within Asia and Australia, smoking was associated with more than a 4-fold increased risk of CD in the Australian Caucasians, yet was not a significant risk factor for the Asians with CD. ${ }^{9}$ In a Japanese study, smoking was identified as an independent risk factor for initial surgery in patients with CD, although the results are uncertain given that this was a single-center retrospective study. ${ }^{10}$ Thus, the exact role of cigarette smoking in conferring susceptibility to or increasing the severity of CD in Asian populations is less well established than it is in Caucasian populations. ${ }^{11,12}$

\section{Surgery, Hospitalization, Intestinal Failure, and Permanent Stoma in CD}

\begin{tabular}{|c|c|}
\hline Summary statement & $\begin{array}{l}\text { Average agreement } \\
\text { score and rate of } \\
\text { agreement }\end{array}$ \\
\hline $\begin{array}{l}\text { 1. Surgery risk increases for people less } \\
\text { than } 40 \text { years at the time of diagnosis } \\
\text { (EL2). Surgery risk is lower if CD is di- } \\
\text { agnosed in early childhood (EL3) and } \\
\text { in old age (EL2). }\end{array}$ & $7.0(75 \%)$ \\
\hline $\begin{array}{l}\text { 2. Surgery risk is higher for small-intesti- } \\
\text { nal lesions (in comparison with large- } \\
\text { intestinal lesions) (EL2). }\end{array}$ & $8.5(100 \%)$ \\
\hline $\begin{array}{l}\text { 3. Penetrating and stricturing pheno- } \\
\text { types at diagnosis are independent } \\
\text { risk factors for surgery compared to } \\
\text { inflammatory type (EL2). }\end{array}$ & $8.2(90 \%)$ \\
\hline $\begin{array}{l}\text { 4. Severe ulcers at colonoscopy in pa- } \\
\text { tients with colonic CD may predict } \\
\text { need for surgery (EL4). }\end{array}$ & $7.8(95 \%)$ \\
\hline $\begin{array}{l}\text { 5. Compared to inflammatory type, fis- } \\
\text { tulizing and stricturing phenotypes } \\
\text { are predictive factors for hospitaliza- } \\
\text { tion and re-hospitalization (EL2). }\end{array}$ & $8.5(95 \%)$ \\
\hline $\begin{array}{l}\text { 6. L4 lesions are a predictor of increased } \\
\text { hospitalization and hence might be a } \\
\text { more serious subgroup (EL3). By con- } \\
\text { trast, large-intestinal lesions predict } \\
\text { a decrease in the hospitalization rate } \\
\text { (EL2). }\end{array}$ & $7.5(86 \%)$ \\
\hline $\begin{array}{l}\text { 7. Penetrating disease and younger age } \\
\text { at diagnosis may predict increased risk } \\
\text { of intestinal failure; bowel-sparing } \\
\text { surgery and cases without stoma in- } \\
\text { volvement may protect against intes- } \\
\text { tinal failure (EL3). }\end{array}$ & $7.7(92 \%)$ \\
\hline $\begin{array}{l}\text { 8. Complex perianal fistulae, anal-canal } \\
\text { stricture, perineal lesions, large peri- } \\
\text { anal abscesses, fecal incontinence, and } \\
\text { distal bowel lesions are risk factors for } \\
\text { permanent stoma (EL3). }\end{array}$ & $8.3(100 \%)$ \\
\hline
\end{tabular}

The prognosis of CD, such as the rate of initial surgery, is similar in Japan to that in Western countries. ${ }^{10}$ As reported by the international consensus statement ${ }^{1}$ and supported by numerous studies conducted in Western populations, prognostic factors for surgery include younger age at diagnosis (except in pediatric patients), ileal/ileocolonic or jejunal disease location, and penetrating and stricturing disease. A Japanese hospital-based cohort study of patients with CD found that B2 or B3 behavior at diagnosis, adjusted for age, 
sex, smoking, and drinking, entailed a higher risk of initial surgery compared with patients with $\mathrm{B} 1$ behavior. ${ }^{10}$ Patients with L4 at the time of diagnosis had more B2 behavior and moderate to severe jejunal stenosis. Japanese patients with L4 at the time of diagnosis may thus be a high-risk group for initial surgery. In Western patients with $\mathrm{CD}$, factors associated with time to first hospitalization include ileocolonic, ileal, and upper gastrointestinal disease relative to colonic extent alone. $^{13}$

As reported by the international consensus statement, ${ }^{1}$ factors associated with permanent stoma include anal-canal stenosis, perineum involvement, perianal fistulae and sepsis, fecal incontinence, and distal colonic CD.

\section{Disease Progression in UC}

\begin{tabular}{|c|c|}
\hline Summary statement & $\begin{array}{l}\text { Average agreement } \\
\text { score and rate of } \\
\text { agreement }\end{array}$ \\
\hline $\begin{array}{l}\text { 1. Family history of IBD (EL3), nonsmoker, } \\
\text { nonresponsiveness to treatment (fre- } \\
\text { quent relapses), and need for systemic } \\
\text { steroids or immunosuppression ther- } \\
\text { apy are related to an increased risk of } \\
\text { proximal disease extension in UC (EL4). }\end{array}$ & $7.1(78 \%)$ \\
\hline $\begin{array}{l}\text { 2. Being young at the time of diagnosis } \\
\text { is a predictive factor for extensive } \\
\text { colitis (EL4). }\end{array}$ & $8.0(100 \%)$ \\
\hline
\end{tabular}

In UC, proximal disease extension is an important risk factor for disease progression. ${ }^{14-16}$ A slightly higher proportion of extensive colitis is found in Western countries than in Asia, with Asian patients generally having a milder disease course compared with their Western counterparts. ${ }^{3}$ A retrospective study showed a higher risk of proximal extension in nonsmokers, patients with $>3$ relapses a year, and those requiring systemic steroids or immunosuppressives. ${ }^{17}$

In Japanese patients, UC disease severity has been shown to be worse in patients with a family history, ${ }^{18}$ although another Japanese study, in children with UC, did not find an association between family history and clinical symptoms. ${ }^{19} \mathrm{~A}$ Japanese study relying upon a large nationwide registry existing since 1975 found that male sex, age $<17$ years, mushy stools, frequent bowel movements, extensive lesions (leftsided colitis or pancolitis), being overweight or obese, and mild or moderate-to-severe hematochezia were positively associated with UC exacerbation. ${ }^{20}$

In Korean patients with ulcerative proctitis, more severe disease at diagnosis predicted proximal disease extension; ${ }^{16}$ another Korean study showed that patients with UC diagnosed at a young age had more severe disease activity. ${ }^{21}$ The situation is similar in Japan, with disease extension being significantly higher in patients with disease onset before age 25 years. ${ }^{22}$ Patients with UC diagnosed at a younger age have a higher risk of disease progression. ${ }^{14}$

\section{Acute Severe UC}

\begin{tabular}{|lc|}
\hline \multicolumn{1}{|c}{ Summary statement } & $\begin{array}{c}\text { Average agreement } \\
\text { score and rate of } \\
\text { agreement }\end{array}$ \\
\hline 1. Extensive lesion(s) is a risk factor for \\
acute severe UC (EL2). \\
2. Comorbid primary sclerosing cholangi- \\
tis is a protective factor for hospital- \\
ization due to UC exacerbation (EL2). \\
Cessation of smoking is a risk factor \\
for UC exacerbation (EL2). \\
3. Extensive disease and cytomegalovirus \\
infection are risk factors for hospital- \\
ization due to UC exacerbation (EL3).
\end{tabular}

Acute severe UC is a potentially life-threatening condition treated by hospitalization and intravenous steroids. ${ }^{23}$ There are few studies examining predictive factors for acute severe UC, although a U.K. study showed that a quarter of patients with UC have at least one episode of acute severe UC and that patients with more extensive lesions have a more frequent occurrence of acute severe flare. ${ }^{24}$ Although younger age at diagnosis was shown to be a risk factor for acute severe disease ( 36 years vs. 39 years, $P=0.049$ ), ${ }^{24}$ the definition of young age is vague and varies depending on the study.

A study in 139 Japanese patients found that total colonoscopic findings on sites of abnormality were the only baseline (i.e., at onset of UC) characteristics significantly related to the need for hospitalization. ${ }^{25}$ Patients with UC with primary sclerosing cholangitis (PSC) ${ }^{26}$ and those who smoke ${ }^{27}$ have less hospitalizations. In Japan, physicians routinely test for cytomegalovirus infection as a factor possibly exacerbating UC flares. ${ }^{28}$ Rates of concurrent cytomegalovirus infection in a Japanese hospital were significantly higher (by 8 times) in patients hospitalized for UC aggravation versus those not hospitalized. ${ }^{29}$ 


\section{Colectomy in UC}

\begin{tabular}{|lc|}
\hline Summary statement & $\begin{array}{c}\text { Average agreement } \\
\text { score and rate of } \\
\text { agreement }\end{array}$ \\
\hline $\begin{array}{l}\text { 1. Pancolitis, long disease duration (EL3), } \\
\text { severity at the time of first hospitaliza- } \\
\text { tion (EL3), endoscopic severity (EL1), } \\
\text { and frequent hospitalization (EL3) are } \\
\text { clinical predictive factors for colectomy. }\end{array}$ \\
2. Physician and surgeon experience, the \\
treatment and surveillance policy, and \\
the patient's preference may affect the \\
final decision to have a colectomy (EL5). \\
\hline
\end{tabular}

Colectomy is a strong indicator of disease severity. ${ }^{30} \mathrm{Be}-$ cause colectomy can be performed as part of acute surgery or elective surgery, rates for colectomy vary based on country and setting. ${ }^{31-34}$ Pancolitis in children has been shown to predict colectomy. ${ }^{35}$ European and Scandinavian studies have demonstrated a relationship between long disease duration and the extent of colitis at diagnosis with the risk of colectomy. ${ }^{31,36,37}$ As indicated by a meta-analysis, mucosal healing is associated with long-term clinical remission and the need for colectomy. ${ }^{38}$ Based on expert opinion, the decision to have a colectomy reflects a number of factors, including patient preferences.

\section{Colorectal Carcinoma and Dysplasia in IBD}

\begin{tabular}{|lc|}
\hline Summary statement & $\begin{array}{c}\text { Average agreement } \\
\text { score and rate of } \\
\text { agreement }\end{array}$ \\
\hline 1. Longer disease duration and extensive \\
disease are related to a higher risk of \\
CRC development in IBD (EL2). There \\
is a need for surveillance for colitis- \\
associated dysplasia/cancer in patients \\
with macroscopically or microscopi- \\
cally active inflammation. \\
2. PSC is related to the development \\
of dysplasia and CRC in UC. At the \\
time of diagnosis of the complica- \\
tion, surveillance with colonoscopy \\
is necessary (EL2). In Japan, there are \\
much fewer UC cases with comorbid \\
PSC compared with Western countries \\
(EL3). However, surveillance and cau- \\
tion towards the development of CRC \\
still seem necessary.
\end{tabular}

3. Histological inflammation score is related to dysplasia and CRC occurring in UC (EL3). Therefore, surveillance should now be considered based on past disease activity.

4. Family history of sporadic CRC in immediate family members is related to the onset of CRC in IBD (EL3). However, there are no data confirming this for Japan.

5. Surveillance is required for rectal cancer and fistula cancer with regards to CD patients with intractable anal lesions (EL3).

Japan currently has no consensus for a cancer surveillance program in patients with $\mathrm{CD}^{39}$ yet a need for consensus exists. The importance of surveillance colonoscopy in patients with long-standing UC in Japan has been well recognized. ${ }^{40,41}$

As reported in the international consensus statement, ${ }^{1}$ longer duration of IBD and greater extent of colonic involvement at diagnosis were found to be independent risk factors for the development of CRC or high-grade dysplasia. A retrospective study of Japanese patients with CD found an increased risk of cancer, particularly $\mathrm{CRC}{ }^{42}$ confirming findings from Western patients. The risk of CRC in Japanese patients with long-standing $\mathrm{CD}$ has been reported to be similar to that of Western patients with $\mathrm{CD} .{ }^{43}$

Proximal disease extension in Japanese patients with UC with proctitis may be associated with an increased CRC risk. ${ }^{22}$ As previously reported in Western populations, a single-center study of Japanese patients with UC confirmed that development of CRC occurred more often in patients with long-standing UC and with UC more extensive than left-sided colitis. ${ }^{44}$ Compared to an age- and sex-matched healthy population, at a tertiary referral center for IBD in Japan, significant risk factors for the development of CRC in patients with CD included female sex, positive history of surgery, observation period $>20$ years, onset of $\mathrm{CD}$ at $<25$ years of age, mixed small and large bowel type, and presence of anal disease. ${ }^{43}$

Numerous studies, as reported in the international consensus statement, ${ }^{1}$ have shown that comorbid PSC strongly predicts dysplasia or CRC development, warranting surveillance. Although the prevalence of comorbid PSC was estimated to be $<1 \%$ in Japan, ${ }^{45}$ surveillance and caution towards the development of CRC is warranted.

Histologic inflammation is a risk factor for progression to CRC in patients with UC. ${ }^{46,47}$ A meta-analysis includ- 
ing 31,287 Asian patients with UC found a $0.02 \%$ (95\% CI, 0.00-0.04) risk of CRC at 10 years, $4.81 \%$ (3.26-6.36) at 20 years, and $13.91 \%(7.09-20.72)$ at 30 years, similar to that of North America and Europe. ${ }^{48}$ In Japan, the number of patients with UC-associated CRC diagnosed by surveillance colonoscopy has increased, with many detected in the very early stages. ${ }^{41}$ Surveillance colonoscopy in Japanese patients with UC has thus proved efficient by detecting CRC in the earlier stages. In Japan, a targeted biopsy strategy is more common than conventional random biopsies for surveillance of UC-associated CRC, as recently reported by a randomized controlled trial. ${ }^{49}$

In Japanese patients with $\mathrm{CD}$, perianal diseases were the most frequent complications; ${ }^{50} 15 \%$ of Japanese patients with CD had an anal fistula ${ }^{10}$ and $55 \%$ of Japanese patients with CD with lower gastrointestinal cancer had cancer in their anorectal regions. ${ }^{51}$ Because rectal and fistula cancer could occur in patients with CD with intractable anal lesions, ${ }^{52}$ further investigation to develop the surveillance program is needed. In Japan, cancer associated with CD more often occurs on the left side of the colon and particularly in the rectum and anal canal. ${ }^{53}$ Screening for perianal cancer, such as with anal canal biopsy, ${ }^{53}$ may be recommended based on the higher incidence of perianal lesions and cancers associated with CD in Japanese patients ${ }^{51}$ compared with patients in Western countries. ${ }^{54}$

\section{DISCUSSION}

Optimization of the treatment strategy for patients with IBD or identifying high-risk patients that require early intervention is important to prevent long-term poor outcomes. Earlier recognition of risks for exacerbation in patients with UC could enable precautious optimal care. ${ }^{20}$ Similarly, identification of factors predictive of a disabling course of CD could point to the need for earlier "top-down" intensive therapy. $^{7}$

This Japanese consensus statement was created because a variety of factors related to prognosis differ between the Japanese setting and Western settings. These include socioeconomic factors such as access to medical treatment and insurance coverage. Because of regulatory requirements, Japan has been conducting a variety of trials specifically in Japanese patients with IBD. In Japan, IBD diagnosis and treatment also differ from that in the West and other countries in East Asia., ${ }^{2,28}$ For example, because of economic and geographic factors, access to specialist centers in Japan is easier compared with other countries, both in the East and in the West, which may influence differences in diagnosis and treatment. In Japan, upper gastrointestinal endoscopy is more likely to be actively performed in patients with CD, with characteristic gastric and duodenal lesions secondary features of the diagnostic criteria. Leukocyte apheresis is approved in Japan, whereas it is not commonly used in other countries; budesonide was not approved in Japan at the time of the meeting; and anti-tumor necrosis factor therapy for postoperative patients with $\mathrm{CD}$ with a high risk of recurrence is actively performed in Japan. Because of Japan's public health system, a patient's economic considerations do not affect the use of anti-tumor necrosis factor drugs.

Genetic and other patient-related factors also differ between Japanese patients with IBD and those in the West. Consequently, some statements included in the international statement were not included here for lack of relevance. For example, NOD2/CARD15 polymorphism and positive antiSaccharomyces cerevisiae antibodies increase the risk of surgery: $:^{55,56}$ this does not apply to patients in Japan because of the absence of these polymorphisms ${ }^{6}$ and the lack of evidence in Japanese patients with CD. Thus, it was not included as a statement. Also, although serum immune responses, such as circulating antibodies against bacterial antigens, are associated with complicated $\mathrm{CD}^{57}$ and predict rapid disease progression $^{58}$ this testing has not been proven to be useful among Japanese patients and is therefore rarely done in clinical practice in Japan. With respect to UC, unlike the international consensus statement, the Japanese experts did not feel that a delay in diagnosis of $>6$ months merited inclusion as a factor related to an increase in the risk of proximal disease extension because the study upon which it was based was in a pediatric population. ${ }^{15}$ Comorbid PSC is reported to be associated with an increased risk of proximal disease extension, ${ }^{14}$ may be a protective factor for hospitalization, ${ }^{26}$ and is also a risk factor for colectomy, primarily because of the associated risk of colorectal neoplasia in the Western population. ${ }^{59}$ However, the prevalence of comorbid PSC was estimated to be $<1 \%$ in Japan, which is significantly lower than the rates in North American and European countries. ${ }^{45}$ Also, unique features of Japanese patients with PSC compared with those in the West include 2 peaks in age distribution at diagnosis and less comorbid IBD. ${ }^{45}$ Approximately 3 quarters of Western patients with PSC have been reported as also having UC, with the prevalence being over $90 \%$ in some studies, ${ }^{59}$ whereas in Japan, only $34 \%$ of patients with PSC also have UC. ${ }^{45}$ In addition to such epidemiological differences, no relationship was found between the documented colonic manifestations of chronic UC and the presence of 
PSC in Japanese patients. ${ }^{60}$ However, the Japanese experts still believed that caution towards the development of CRC for patients with UC comorbid with PSC is necessary.

This statement was created by consolidating expert opinions based on literature evidence. It is meant to extend the previously published international consensus statement, ${ }^{1}$ contextualized for Japanese patients with IBD and within the Japanese setting. Thus, it may not be applicable to other settings or to other patients. IBD prognostic factors are clinical and have been mostly based on retrospective studies, many conducted over a decade ago. ELs were based on the literature reviews, and in general, reflect the reporting and study design of the studies cited as opposed to the quality of the results. However, combining the literature review with expert opinion, as well as further identification of Japanese patientspecific studies, allowed for contextualization of the results and suggests potential strategies for implementation into clinical practice in Japan. Nonetheless, the dearth of studies on prognostic factors specifically in Japanese patients with IBD merits caution when applying these statements to clinical practice because most of the studies were performed in Western patients under Western treatment paradigms. Future studies, specifically conducted in Japanese patients, will be more effective in uncovering prognostic factors for patients with IBD.

In conclusion, while there were many similarities in specialists' agreement on prognostic factors between Western patients with IBD and Japanese patients with IBD, certain differences exist, of which clinicians caring for Japanese patients with IBD should be aware.

\section{FINANCIAL SUPPORT}

Abbvie paid consultancy fees to the Global Steering Committee for their participation in the Global Steering Committee meeting in Copenhagen, Denmark, and speaker fees to the committee members who presented at the international IBD Ahead meeting in Frankfurt, Germany. Travel to and from these meetings was reimbursed. AbbVie GK paid consultancy fees to the Japan Steering Committee for their participation in the Japan Steering Committee meeting in Tokyo. Editorial support, in the form of medical writing, assembling tables based on the authors' detailed directions, collating author comments, copyediting, fact checking, and referencing, was provided by Steven Tresker, of Cactus Communications, and was funded by AbbVie GK.

\section{CONFLICT OF INTEREST}

All authors other than M.K. received consulting fees and travel support from AbbVie GK. M.K. is an employee of and holds stock options in AbbVie GK. No payments were made to the authors for the development or writing of this manuscript.

AbbVie paid consultancy fees to the Global Steering Committee for their participation in the Global Steering Committee meeting in Copenhagen, Denmark, and speaker fees to the committee members who presented at the international IBD Ahead meeting in Frankfurt, Germany. Travel to and from these meetings was reimbursed. The bibliographic fellows were paid consultancy fees by AbbVie to conduct the literature reviews. AbbVie GK paid consultancy fees to the Japan Steering Committee for their participation in the Japan Steering Committee meeting in Tokyo. No payments were made to the authors for the development or writing of this manuscript. Editorial support, in the form of medical writing, assembling tables based on the authors' detailed directions, collating author comments, copyediting, fact checking, and referencing, was provided by Steven Tresker, of Cactus Communications, and was funded by AbbVie GK.

\section{AUTHOR CONTRIBUTION}

Conceptualization: TK, Tadakazu Hisamatsu. Investigation: TK, Tadakazu Hisamatsu, YS, HO, AA, TA, RH, Hideki Iijima, Hiroki Ikeuchi, YI, SK, RK, TM, SM, MN, SN, HN, TT, MS, KY, NY, KW, MW, Toshifumi Hibi. Writing - review and editing: all authors. Supervision: Toshifumi Hibi. Project administration: MK. Approval of final manuscript: all authors. All authors meet ICMJE authorship criteria. Neither honoraria nor payments were made for authorship.

\section{REFERENCES}

1. Torres J, Caprioli F, Katsanos KH, et al. Predicting outcomes to optimize disease management in inflammatory bowel diseases. J Crohns Colitis 2016;10:1385-1394.

2. Hida N, Nakamura S, Hahm KB, et al. A questionnaire-based survey on the diagnosis and management of inflammatory bowel disease in East Asian countries in 2012. Digestion 2014;89:88-103.

3. Park SJ, Kim WH, Cheon JH. Clinical characteristics and treatment of inflammatory bowel disease: a comparison of Eastern and Western perspectives. World J Gastroenterol 2014;20:11525-11537. 
4. Prideaux L, Kamm MA, De Cruz PP, Chan FK, Ng SC. Inflammatory bowel disease in Asia: a systematic review. J Gastroenterol Hepatol 2012;27:1266-1280.

5. Fuyuno Y, Yamazaki K, Takahashi A, et al. Genetic characteristics of inflammatory bowel disease in a Japanese population. J Gastroenterol 2016;51:672-681.

6. Hirano A, Yamazaki K, Umeno J, et al. Association study of 71 European Crohn's disease susceptibility loci in a Japanese population. Inflamm Bowel Dis 2013;19:526-533.

7. Beaugerie L, Seksik P, Nion-Larmurier I, Gendre JP, Cosnes J. Predictors of Crohn's disease. Gastroenterology 2006;130:650656.

8. Leong RW, Lau JY, Sung JJ. The epidemiology and phenotype of Crohn's disease in the Chinese population. Inflamm Bowel Dis 2004;10:646-651.

9. Ng SC, Tang W, Leong RW, et al. Environmental risk factors in inflammatory bowel disease: a population-based case-control study in Asia-Pacific. Gut 2015;64:1063-1071.

10. Sato Y, Matsui T, Yano Y, et al. Long-term course of Crohn's disease in Japan: incidence of complications, cumulative rate of initial surgery, and risk factors at diagnosis for initial surgery. J Gastroenterol Hepatol 2015;30:1713-1719.

11. Arora U, Ananthakrishnan AN, Kedia S, et al. Effect of oral tobacco use and smoking on outcomes of Crohn's disease in India. J Gastroenterol Hepatol 2018;33:134-140.

12. Gearry RB. IBD and environment: are there differences between East and West. Dig Dis 2016;34:84-89.

13. Biroulet LP, Loftus EV, Harmsen WS, Zinsmeister AR, Sandborn WJ. T1299 Emergency room visits and hospitalizations for Crohn's disease in a population-based cohort. Gastroenterol 2010;138:S532.

14. Etchevers MJ, Aceituno M, García-Bosch O, et al. Risk factors and characteristics of extent progression in ulcerative colitis. Inflamm Bowel Dis 2009;15:1320-1325.

15. Gower-Rousseau C, Dauchet L, Vernier-Massouille G, et al. The natural history of pediatric ulcerative colitis: a populationbased cohort study. Am J Gastroenterol 2009;104:2080-2088.

16. Kim B, Park SJ, Hong SP, Kim TI, Kim WH, Cheon JH. Proximal disease extension and related predicting factors in ulcerative proctitis. Scand J Gastroenterol 2014;49:177-183.

17. Meucci G, Vecchi M, Astegiano M, et al. The natural history of ulcerative proctitis: a multicenter, retrospective study. Gruppo di Studio per le Malattie Infiammatorie Intestinali (GSMII). Am J Gastroenterol 2000;95:469-473.

18. Kuwahara E, Asakura K, Nishiwaki Y, et al. Effects of family history on inflammatory bowel disease characteristics in Japanese patients. J Gastroenterol. 2012 ;47:961-968.
19. Fujii T, Sato M, Hosoi K, et al. Assessment of the family history of patients with ulcerative colitis at a single center in Japan. J Pediatr Gastroenterol Nutr 2016;63:512-515.

20. Kuwahara E, Murakami Y, Nakamura T, et al. Factors associated with exacerbation of newly diagnosed mild ulcerative colitis based on a nationwide registry in Japan. J Gastroenterol 2017;52:185-193.

21. Lee JH, Cheon JH, Moon CM, et al. Do patients with ulcerative colitis diagnosed at a young age have more severe disease activity than patients diagnosed when older? Digestion 2010;81:237243.

22. Anzai H, Hata K, Kishikawa J, et al. Clinical pattern and progression of ulcerative proctitis in the Japanese population: a retrospective study of incidence and risk factors influencing progression. Colorectal Dis 2016;18:097-0102.

23. Chen JH, Andrews JM, Kariyawasam V, et al. Review article: acute severe ulcerative colitis - evidence-based consensus statements. Aliment Pharmacol Ther 2016;44:127-144.

24. Dinesen LC, Walsh AJ, Protic MN, et al. The pattern and outcome of acute severe colitis. J Crohns Colitis 2010;4:431-437.

25. Kuno T, Kojima Y, Mochizuki H, et al. Factors predicting subsequent hospitalization in patients with ulcerative colitis: total colonoscopic findings are the strongest predictor. Hepatogastroenterology 2015;62:821-824.

26. Moayyeri A, Daryani NE, Bahrami H, Haghpanah B, NayyerHabibi A, Sadatsafavi M. Clinical course of ulcerative colitis in patients with and without primary sclerosing cholangitis. J Gastroenterol Hepatol 2005;20:366-370.

27. Odes HS, Fich A, Reif S, et al. Effects of current cigarette smoking on clinical course of Crohn's disease and ulcerative colitis. Dig Dis Sci 2001;46:1717-1721.

28. Nakase H, Keum B, Ye BD, Park SJ, Koo HS, Eun CS. Treatment of inflammatory bowel disease in Asia: the results of a multinational web-based survey in the 2(nd) Asian Organization of Crohn's and Colitis (AOCC) meeting in Seoul. Intest Res 2016;14:231-239.

29. Matsumoto S, Yoshida Y. What are the factors that affect hospitalization and surgery for aggravation of ulcerative colitis? Eur J Gastroenterol Hepatol 2014;26:282-287.

30. Monstad I, Hovde O, Solberg IC, Moum BA. Clinical course and prognosis in ulcerative colitis: results from population-based and observational studies. Ann Gastroenterol 2014;27:95-104.

31. Hoie O, Wolters FL, Riis L, et al. Low colectomy rates in ulcerative colitis in an unselected European cohort followed for 10 years. Gastroenterology 2007;132:507-515. 
32. Kaplan GG, Seow CH, Ghosh S, et al. Decreasing colectomy rates for ulcerative colitis: a population-based time trend study. Am J Gastroenterol 2012;107:1879-1887.

33. Langholz E, Munkholm P, Davidsen M, Binder V. Course of ulcerative colitis: analysis of changes in disease activity over years. Gastroenterology 1994;107:3-11.

34. Targownik LE, Singh H, Nugent Z, Bernstein CN. The epidemiology of colectomy in ulcerative colitis: results from a population-based cohort. Am J Gastroenterol 2012;107:1228-1235.

35. Falcone RA Jr, Lewis LG, Warner BW. Predicting the need for colectomy in pediatric patients with ulcerative colitis. J Gastrointest Surg 2000;4:201-206.

36. Romberg-Camps MJ, Dagnelie PC, Kester AD, et al. Influence of phenotype at diagnosis and of other potential prognostic factors on the course of inflammatory bowel disease. Am J Gastroenterol 2009; 104:371-383.

37. Solberg IC, Lygren I, Jahnsen J, et al. Clinical course during the first 10 years of ulcerative colitis: results from a populationbased inception cohort (IBSEN Study). Scand J Gastroenterol 2009;44:431-440.

38. Shah SC, Colombel JF, Sands BE, Narula N. Mucosal healing is associated with improved long-term outcomes of patients with ulcerative colitis: a systematic review and meta-analysis. Clin Gastroenterol Hepatol 2016;14:1245-1255.e8.

39. Ueno F, Matsui T, Matsumoto T, et al. Evidence-based clinical practice guidelines for Crohn's disease, integrated with formal consensus of experts in Japan. J Gastroenterol 2013;48:31-72.

40. Hata K, Kishikawa J, Anzai H, et al. Surveillance colonoscopy for colitis-associated dysplasia and cancer in ulcerative colitis patients. Dig Endosc 2016;28:260-265.

41. Matsuoka H, Ikeuchi H, Uchino M, et al. Clinicopathological features of ulcerative colitis-associated colorectal cancer pointing to efficiency of surveillance colonoscopy in a large retrospective Japanese cohort. Int J Colorectal Dis 2013;28:829-834.

42. Mizushima T, Ohno Y, Nakajima K, et al. Malignancy in Crohn's disease: incidence and clinical characteristics in Japan. Digestion 2010;81:265-270.

43. Yano Y, Matsui T, Uno H, Hirai F, Futami K, Iwashita A. Risks and clinical features of colorectal cancer complicating Crohn's disease in Japanese patients. J Gastroenterol Hepatol 2008;23:1683-1688.

44. Fujita T, Ando T, Watanabe O, et al. Clinicopathological study of colorectal cancer occurring in patients with ulcerative colitis: results from a single hospital in Japan. Hepatogastroenterology 2010;57:487-492.

45. Tanaka A, Takikawa H. Geoepidemiology of primary sclerosing cholangitis: a critical review. J Autoimmun 2013;46:35-40.
46. Gupta RB, Harpaz N, Itzkowitz S, et al. Histologic inflammation is a risk factor for progression to colorectal neoplasia in ulcerative colitis: a cohort study. Gastroenterology 2007;133:10991105.

47. Rubin DT, Huo D, Kinnucan JA, et al. Inflammation is an independent risk factor for colonic neoplasia in patients with ulcerative colitis: a case-control study. Clin Gastroenterol Hepatol 2013;11:1601-1608.e4.

48. Bopanna S, Ananthakrishnan AN, Kedia S, Yajnik V, Ahuja V. Risk of colorectal cancer in Asian patients with ulcerative colitis: a systematic review and meta-analysis. Lancet Gastroenterol Hepatol 2017;2:269-276.

49. Watanabe T, Ajioka Y, Mitsuyama K, et al. Comparison of targeted vs random biopsies for surveillance of ulcerative colitisassociated colorectal cancer. Gastroenterology 2016;151:11221130.

50. Oriuchi T, Hiwatashi N, Kinouchi Y, et al. Clinical course and longterm prognosis of Japanese patients with Crohn's disease: predictive factors, rates of operation, and mortality. J Gastroenterol 2003;38:942-953

51. Shinozaki M. Crohn's disease and intestinal cancer in Japan. Nippon Daicho Komonbyo Gakkai Zasshi 2008;61:353-363.

52. Ky A, Sohn N, Weinstein MA, Korelitz BI. Carcinoma arising in anorectal fistulas of Crohn's disease. Dis Colon Rectum 1998;41:992-996

53. Higashi D, Katsuno H, Kimura H, et al. Current state of and problems related to cancer of the intestinal tract associated with Crohn's disease in Japan. Anticancer Res 2016;36:37613766.

54. Delaunoit T, Limburg PJ, Goldberg RM, Lymp JF, Loftus EV Jr. Colorectal cancer prognosis among patients with inflammatory bowel disease. Clin Gastroenterol Hepatol 2006;4:335-342.

55. Adler J, Rangwalla SC, Dwamena BA, Higgins PD. The prognostic power of the NOD2 genotype for complicated Crohn's disease: a meta-analysis. Am J Gastroenterol 2011;106:699-712.

56. Zhang Z, Li C, Zhao X, et al. Anti-Saccharomyces cerevisiae antibodies associate with phenotypes and higher risk for surgery in Crohn's disease: a meta-analysis. Dig Dis Sci 2012;57:29442954.

57. Mow WS, Vasiliauskas EA, Lin YC, et al. Association of antibody responses to microbial antigens and complications of small bowel Crohn's disease. Gastroenterology 2004;126:414-424.

58. Dubinsky MC, Lin YC, Dutridge D, et al. Serum immune responses predict rapid disease progression among children with Crohn's disease: immune responses predict disease progression. Am J Gastroenterol 2006;101:360-367. 
59. de Vries AB, Janse M, Blokzijl H, Weersma RK. Distinctive inflammatory bowel disease phenotype in primary sclerosing cholangitis. World J Gastroenterol 2015;21:1956-1971.
60. Hashimoto E, Ideta M, Taniai M, et al. Prevalence of primary sclerosing cholangitis and other liver diseases in Japanese patients with chronic ulcerative colitis. J Gastroenterol Hepatol 1993;8:146-149. 